\title{
Vector Electronystagmography Analysis in Elderly Individuals with Dizziness Complaint
}

\author{
Lidiane Maria de Brito Macedo Ferreira ${ }^{1}$ Karyna Mirelly O. B. de Figueiredo Ribeiro ${ }^{2}$ André Pestana $^{3}$ \\ Arthur Jorge de Vasconcelos Ribeiro ${ }^{4}$ Kenio Costa de Lima ${ }^{5}$
}

\footnotetext{
1 Department of Otolaryngology, Universidade Fedreral do Rio Grande do Norte (UFRN), Natal/RN, Brazil

${ }^{2}$ Department of Physiotherapy, Universidade Fedreral do Rio Grande do Norte (UFRN), Natal/RN, Brazil

${ }^{3}$ Department of Audiology, Universidade Potiguar (UnP), RN, Brazil

${ }^{4}$ Division of Neurology, Department of Pediatrics, Universidade Federal do Rio Grande do Norte (UFRN), Natal/RN, Brazil

${ }^{5}$ Department of Public Health, Universidade Federal do Rio Grande do Norte (UFRN), Natal/RN, Brazil
}

Int Arch Otorhinolaryngol 2013;17:380-382.

\begin{abstract}
Address for correspondence Lidiane Maria de Brito Macedo Ferreira, Universidade Federal do Rio Grande do Norte, Av. Campos Sales, 682, AP 1302, Natal/RN, Brazil (e-mail: lidianembm@yahoo.com.br).
\end{abstract}

\author{
Abstract \\ Keywords \\ - aged \\ - dizziness \\ - medical examination
}

Introduction Vector electronystagmography is widely used to evaluate vestibular function; however, elderly patients may show changes not due to vestibular disorders. Aim This study aims to characterize vector electronystagmography tests in the elderly participants in a service station of the Brazilian public health system, the Unified Health System (SUS) in the city of Natal, who presented with dizziness.

Methods A cross-sectional and clinical study to characterize the vector electronystagmography in 10 members of an elderly SUS referral center located in the city of Natal with dizziness.

Results Of 10 patients interviewed, 9 were women, and just 1 was a man. All complained of dizziness in the last year, and most of them had more than one type of dizziness. The main differential diagnosis was benign paroxysmal positional vertigo. Regarding vector electronystagmography, we found $20 \%$ of patients with semispontaneous nystagmus in at least one direction and changes in saccades latency in $100 \%$ of patients, with $20 \%$ in relation to the accuracy of pendular tracking changes at the frequency of $0.2 \mathrm{~Hz}, 10 \%$ at $0.4 \mathrm{~Hz}$, and $80 \%$ at $0.8 \mathrm{~Hz}$, and $10 \%$ change in optokinetic gain. No patient had altered caloric test.

Conclusion Vector electronystagmography alterations in the elderly do not always indicate disease.

\section{Introduction}

Vestibular dysfunction, or vestibulopathy, comprises disorders of the vestibular system in the peripheral (labyrinth or cochlear nerve) and/or central (nuclei, pathways, and central nervous system interrelationships). When the condition is determined by impairment of the inner ear (labyrinth), it is called labyrinthopathy. ${ }^{1}$
Among the elderly with chronic vestibular disease, 53.3\% fall every year, ${ }^{2}$ and vertigo is the most common cause, occurring in $25 \%$ of episodes. ${ }^{3}$ It is important to remember that polypharmacotherapy, for various pathologies, also can cause falls among the elderly, either by side effects of drugs (hypotension, sedation, confusion, altered motor reflexes) or by its associations. ${ }^{4}$ received

January 10, 2013

accepted

June 25, 2013
Copyright $\odot 2013$ by Thieme Publicações DOI http://dx.doi.org/ Ltda, Rio de Janeiro, Brazil

$10.1055 / \mathrm{s}-0033-1353139$ ISSN $1809-9777$. 
Being multifactorial and closely related to systemic changes and to the patient's habits (drinking, smoking, stimulant use, or hyperkalemic diet), vestibulopathy is difficult to diagnose; it is often diagnosed by exclusion, and therefore treatment is difficult. Accurate diagnosis is not always achieved, and only the syndromic diagnosis will guide clinical practice.

Clinically, there are several ways to detect the imbalance and seek its causes to prevent complications such as falls. Vertigo is evaluated by anamnesis and otoneurologic clinical exam (with evaluation of the cranial nerves, cerebellum, and static and dynamic balance), laboratory tests (such as biochemical tests), audiological tests (audiometry, immittance, otoacoustic emissions, and brainstem evoked potentials), vestibular auxiliary exam (vector electronystagmography), and, if necessary, imaging studies (computed tomography and magnetic resonance image). It should be remembered that, depending on the patient's comorbidities, other laboratory tests are needed for diagnosis and/or monitoring of base pathologies.

The vector electronystagmography is a widely used exam in clinical practice; however, it has limitations related to the health condition of the patient (patients too debilitated may not undergo the test), especially the elderly, with their fragility and comorbidities. Moreover, the geriatric patient often presents degeneration of the vestibular, oculomotor, or proprioceptive systems, which generate abnormal results in vector electronystagmography but which in reality do not reflect the pathologic condition but physiology. The objective of this study is to characterize vector electronystagmography exams in elderly participants from a service station of the Brazilian public health system, the Unified Health System (SUS) in the city of Natal, who complain of dizziness.

\section{Methods}

A sectional study was conducted to characterize the vector electronystagmography of 10 elderly patients with dizziness. These patients are participants at a SUS referral center located in the city of Natal.

The subjects were chosen at random when questioned for the occurrence of dizziness in the last year. Subjects 60 years or older, with good cognitive level, able to walk without walking aids, and with dizziness complaint in the last year were included. Subjects with decompensated diseases and those who did not have exams by the scheduled date were excluded.

Patients underwent a clinical history and otoneurologic physical examination and then had the vector electronystagmography test.

Equipment used for vector electronystagmography included the computed electronystagmography system and an otoneurologic stimulator e-96 (Contronic, Brazil). The steps of the exam were performed according to criteria proposed by Mangabeira-Albernaz et $\mathrm{al}^{5}$ : calibration of ocular movements, spontaneous and semispontaneous nystagmus registration, analysis of saccadic movements, analysis of pendular tracking, optokinetic gain, and analysis of preand post-caloric test (with water) nystagmus.
Dizziness was classified according to the classification of Drachman and Hart. ${ }^{6}$ Physical examination consisted of otoscopy, evaluation tests of static balance (Romberg and Romberg-Barrè test), dynamic balance (proof of Fukuda and Babinski-Weil), evaluation tests of coordination (finger-nose and finger-nose-finger tests and diadochokinesis), evaluation of spontaneous and semispontaneous nystagmus, evaluation of vestibulo-ocular reflex, dynamic visual acuity, head shake, head impulse, vibration-induced nystagmus, roll test, and Dix-Hallpike maneuver. We also evaluated the cervical region through physiotherapy maneuvers to assess cervical causes for the dizziness. The etiologic diagnosis was made based on this physical examination and blood pressure control, along with the history of comorbidities and medications used.

The study was approved by the Ethics Committee under number 309/2012 of the institution, and all patients signed an informed consent form prior to data collection. It was made a descriptive statistics for data analysis.

\section{Results}

Of the 10 patients interviewed, 9 were women and only 1 was a man. All complained of dizziness in the last year, and most of them had more than one type of dizziness ( $\mathbf{- T a b l e ~} \mathbf{1}$ ).

The most common etiologic diagnosis of dizziness was benign paroxysmal positional vertigo (BPPV; - Table 2 ).

Regarding vector electronystagmography, we found that changes in saccades and pendular tracking were the most common findings, and no patient had abnormal caloric proof (-Table 3).

\section{Discussion}

The study group consisted of elderly patients with dizziness in the last year, not necessarily vertigo, so we can conclude that not all had labyrinthopathy. This became clear when considering the types of dizziness: several patients had presyncope, floating sensation, and imbalance, which refer, in most cases, to causes of dizziness not associated to the labyrinth. However, in general, vertigo was the most frequent type, alone or combined. This finding is confirmed by the literature,

Table 1 Classification of types of dizziness in elderly individuals

\begin{tabular}{|l|l|}
\hline Type of dizziness & Number of patients \\
\hline Vertigo & 1 \\
\hline Disequilibrium & 2 \\
\hline Presyncope & 1 \\
\hline Floating sensation + presyncope & 1 \\
\hline Vertigo + disequilibrium & 2 \\
\hline Vertigo + floating sensation & 1 \\
\hline $\begin{array}{l}\text { Vertigo + floating } \\
\text { sensation + presyncope }\end{array}$ & 1 \\
\hline $\begin{array}{l}\text { Vertigo + disequilibrium }+ \\
\text { presyncope }\end{array}$ & 1 \\
\hline
\end{tabular}


Table 2 Etiologic diagnosis of dizziness in elderly individuals

\begin{tabular}{|l|l|}
\hline Diagnosis & Number of patients \\
\hline BPPV & 6 \\
\hline Cervical syndrome & 2 \\
\hline Cardiovascular alterations & 2 \\
\hline
\end{tabular}

Abbreviation: BPPV, benign paroxysmal positional vertigo.

Table 3 Findings in the vector electronystagmography exams of elderly individuals

Semispontaneous nystagmus in at least one direction: $20 \%$ of the patients

Changes in saccadic movements: $100 \%$ of the patients regarding latency, $20 \%$ in relation to the precision

Changes in pendular tracking: $20 \%$ in the frequency of $0.2 \mathrm{~Hz} ; 10 \%$ in the frequency of $0.4 \mathrm{~Hz} ; 80 \%$ in the frequency of $0.8 \mathrm{~Hz}$

Changes in optokinetic gain: $10 \%$ of the patients

Changes in caloric proof: 0

in which vertigo is identified as corresponding to $60.2 \%$ of cases. $^{7}$

When evaluating the possible causes of dizziness, four patients had nonvestibular causes (two had cervical problems and two, cardiovascular) and most had BPPV, diagnosed by the Dix-Hallpike maneuver. This is a pathology of the labyrinth, with involvement of posterior semicircular canal in most cases.

The vector electronystagmography is a diagnostic test of vestibular disorders; its main stage is the caloric test, which diagnoses lesions of the two labyrinths separately. However, this test is sensitive to changes of the lateral semicircular canals only.

According to our findings, not all patients with BPPV will show changes in the vector electronystagmography, because the topography of the lesion is in different locations from the initial search.

In this study, no patient had abnormal caloric test because we obtained nonvestibular disorders as causes of dizziness, and the only vestibular cause chosen was BPPV, which shows no change in this examination. Felipe et al found normal caloric tests in $72.5 \%$ of their elderly patients. ${ }^{7}$

This is reflected in typical changes of electronystagmography in elderly patients, which occur due to degeneration of the physiologic systems-in other words, caused by oculovestibular and neurologic age-related modifications and reduction of response time and reflexes. As such, the results of this study can be generalized to elderly without vestibular disorders.

Gushikem et al in 2003 found abnormal tests in 68\% of an elderly group without vestibular disease. ${ }^{8}$ In the sample of this study, $100 \%$ had abnormal tests, but it is noteworthy that it was a reduced sample. The change in saccades latency in $100 \%$ of the elderly justifies these changes, and it is due to the slowness of oculomotor responses, not exactly to vestibular disorders.

The micrograph was not found in any examination, although this is described in the literature as a common finding in elderly. ${ }^{8}$

\section{Conclusion}

Most of the evaluated patients had BPPV as etiologic diagnosis for their dizziness, and the most prevalent alteration observed in the vector electronystagmography was the change in latency of saccades (in 100\% of the tests). No patient had altered caloric proof.

\section{References}

1 Ganança MM, Caovilla HH. Desequilíbrio e reequilíbrio. In: Ganança MM, ed. Vertigem tem cura? O que aprendemos nestes últimos 30 anos. São Paulo, Brazil: Lemos Editorial; 1998:13-19

2 Gazzola JM, Ganança FF, Aratani MC, Perracini MR, Ganança MM. Clinical evaluation of elderly people with chronic vestibular disorder. Braz J Otorhinolaryngol 2006;72:515-522

3 Gazzola JM, Ganança FF, Aratani MC, Perracini MR, Ganança MM. Circumstances and consequences of falls in elderly people with vestibular disorder. Braz J Otorhinolaryngol 2006; 72:388-392

4 Fabricio SCC, Rodrigues RAP, Costa Júnior ML. Quedas acidentais em idosos institucionalizados. Acta Paul Enf 2002;15:51-59

5 Mangabeira-Albernaz PL, Ganança MM, Pontes PAL. Modelo operacional do aparelho vestibular. In: Mangabeira-Albernaz PL, Ganança MM, eds. Vertigem. 2nd ed. São Paulo, Brazil: Moderna; 1976:29-36

6 Drachman DA, Hart CW. An approach to the dizzy patient. Neurology 1972;22:323-334

7 Felipe L, Cunha LCM, Cunha FCM, Cintra MTG, Goncalves DU. Presbivertigem como causa de tontura no idoso. Pró Fono R Atual Cient 2008;20:99-104

8 Gushikem P, Caovilla HH, Ganança MM. Avaliação otoneurológica em idosos com tontura. Acta ORL 2003;21:1-7 